\title{
An assessment of functional outcome and management of metacarpal and phalangeal fractures of hand with universal mini external fixator
}

\author{
Addanki Vijayanand, Alam Penchalaih*
}

Department of Orthopaedics, Narayana Medical College, Nellore, Andhra Pradesh, India

Received: 05 April 2020

Revised: 20 April 2020

Accepted: 21 April 2020

\author{
*Correspondence: \\ Dr. Allam penchalaih, \\ E-mail: sujithbhanu1212@gmail.com
}

Copyright: ( $)$ the author(s), publisher and licensee Medip Academy. This is an open-access article distributed under the terms of the Creative Commons Attribution Non-Commercial License, which permits unrestricted non-commercial use, distribution, and reproduction in any medium, provided the original work is properly cited.

\begin{abstract}
Background: Trauma to the hand is quite common and may result in fractures of the bones. Hand fractures can be complicated by deformity from no treatment, stiffness from over treatment and both deformity and stiffness from poor treatment. To evaluate the outcome of metacarpal and phalangeal fractures managed with UMEX (universal mini external fixator) in order to assess their usefulness in different fracture types and to make recommendations regarding potential applications.

Methods: A one-year prospective study at Narayana medical college was conducted and 50 cases were included following the inclusion criteria. All the cases were evaluated and assessment of injury was done by Swnason's criteria. UMEX application was done on all cases and follow up was done and functional assessment done following Duncan's criteria.

Results: Male predominance was observed, 21-40 years was common age group (30\%) and RTA was common cause (72\%). 57 total fractures with $66.7 \%$ in right hand, $45.62 \%$ were metacarpals, $36.84 \%$ proximal phalanx and $80 \%$ were shaft fractures. $61.4 \%$ of cases had radiological union within 8-12 weeks and partial stiffness was the commonest complication (52.17\%). As per the Duncan's criteria, 44\% had good outcome, $40 \%$ had excellent outcome, $10 \%$ had fair and $6 \%$ had poor outcome.

Conclusions: UMEX is an adequate treatment modality for multiple, intra articular and open fractures. Understanding the basic principles and correct application methodology is absolutely essential for optimal usage of the equipment. It's a useful tool in management of small fractures of the hand.
\end{abstract}

Keywords: Metacarpal fractures, UMEX, Duncan's criteria, Swnason's criteria

\section{INTRODUCTION}

Hand of the human being is a complex organ with which interaction occurs. It's stated as complex because of its anatomy and the structures involved which include tendons, nerves and multiple joints. Diseases of the hand are wide in number and variety depending upon the structure involved and the common causes may be due to excessive use and degeneration, trauma and tissue disorders. Trauma to the hand is quite common and may result in fractures of the bones and damage to the tissues, tendons and nerves. Skilled hand surgeons may repair the damaged soft tissues, nerves and skin by using replacement grafts and tissue repairs. However, management of fractures of the bones are quite different depending upon the type, site and pattern of fractures. A wide range of management strategies have been evolved with multiple benefits and disadvantages in treatment plans for fracture of the metacarpals and phalanges. Fractures around hand approximately account for $10 \%$ of all the fractures reporting to the emergency-room and 
outpatients department, $36 \%$ of all the hand fractures are metacarpal fractures. ${ }^{1}$

Workplace related accidents, agricultural accidents, road traffic injuries are the most common causes of fracture of metacarpals and phalanges. Proper and timely management is exactly in need as any mismanagement may result in functional handicap. So, priority step in management include reduction of complications and reunion of bone to maintain full range of functions before injury as early as possible. ${ }^{2}$ Hand fractures can be complicated by deformity from no treatment, stiffness from over treatment and both deformity and stiffness from poor treatment. Management protocols for metacarpal and phalangeal fractures depends upon type, pattern of fractures and may include conservative managements to open reductions with internal fixations using plates, screws and fixator or pinning or casting/slab alone. However nonoperative managements and fixations with k-wire, plates, and screws sometimes lead to further soft tissue damage, stiffness and delay in rehabilitation. In some conditions (e.g., comminuted fractures or complex intra-articular fractures) where internal fixation cannot be possible the role of UMEX (universal mini extractor) which is commonly used in management of fractures of long bones can be applied and studies pertaining its functional outcomes after application are not widely done. ${ }^{3}$

Hence the present study was done to evaluate the outcome of metacarpal and phalangeal fractures managed with UMEX in order to assess their usefulness in different fracture types and to make recommendations regarding potential applications.

\section{METHODS}

The present study was conducted at Narayana Medical College and Hospital, a tertiary care hospital for a period of one year from September 2018 to August 2019. All the cases attending the casualty and admitted in department of orthopaedics with fractures of hand fulfilling the inclusion criteria and exclusion criteria were included in the study. The study protocol was presented before the ethical committee and was approved. The study was conducted as per the guidelines of the committee. Cases in the study were clinically examined by a senior resident of the department and the findings of the examination were noted in a separate predesigned questionnaire sheet. The socio demographic data (age, sex etc), nature of injury, etiology of injury and type of fracture was noted for all the cases in the study. Informed written consent was obtained from all the cases in the study and explained in detail about the study protocol, risks and management protocol.

\section{Inclusion criteria}

Inclusion criteria were patients in the age group of 10 to 60 years, unstable fractures of hand, intra articular fractures and juxtra-articular fractures, open fractures, multiple fractures.

\section{Exclusion criteria}

Exclusion criteria were severely crushed hand injuries, fractures associated with tendon injuries, fractures with associated neurovascular injuries.

Preoperative evaluation of all the included cases was done and routine investigations, surgical profile, preoperative and postoperative radiographs were done. Assessment of the injury was done as per Swanson et al. ${ }^{4}$

Type I: Clean wound without significant contamination or delay in treatment and no significant systemic illness.

Type II: Contamination with gross dirt/debris; delay in treatment for $>24$ hours; significant systemic illness.

Peripheral circulation was assessed by noting colour, temperature, capillary filling and patency of collateral circulation by Aliens test.

Radiography: AP and oblique views and if necessary lateral views were also taken. The level, pattern, angulation and amount of displacement were noted. If necessary, radiographs of other parts were done.

UMEX application: Thorough debridement of the wound was done and depending upon the pattern of fracture and desired pin placement and frame configuration was decided. Placement of pin was done in safe zones to facilitate subsequent dressing in open injuries. Skin and fascia were incised prior to pin insertion and pins were inserted by using hand or power drill. Clamps and side rods were applied. Fracture was reduced by using compression/distraction device. Check X-rays of hand AP and oblique views were taken to study reduction. Postoperative care was taken and active and passive movements of joints proximal and distal to fixator were carried.

Rehabilitation: active and passive movements were carried for 3 weeks and thorough radiological examination was carried by removal of critical connecting rods and testing for union. The frame was removed depending upon presence of pain and abnormal mobility. Cases were followed until six weeks and associated complications were treated if developed. Functional assessment was done based on total range of active movements in each injured finger separately according to Duncan et al. ${ }^{5}$

\section{Statistical analysis}

The collected data was entered in microsoft excel spread sheet and checked for any corrections and analyzed by using GraphPad prism Insta3 for windows. Quantitative data were described by their median and standard deviation or by median and interquartile range (IQR). Qualitative data were described by counts and percentage. Descriptive statistics were shown as mean $\pm \mathrm{SD}$ or number of cases and percentages, where applicable. 


\section{RESULTS}

In the present study for a period of one year, fifty cases of both sexes with age group between 10-60 years were included. Of the total 50 cases, 40 cases were male $(80 \%)$ and 10 cases $(20 \%)$ were females with a male and female ratio of $4: 1$, our study clearly exhibited a male preponderance which is due to male more prone to road accidents, physical activity and risky procedures in a factory setting. Majority of the cases were in the age group of 21-40 years (72\%) and 11-20 years with $16 \%$ and above 41 years with only $12 \%$. Maximum age was 58 years and minimum were 14 years. The mean age of the cases in the study was 28.64 years with a Standard deviation of 6.52 years. Regarding the occupational history of the cases in the study group, $42 \%$ were workers, $16 \%$ were drivers and housewives each, $12 \%$ were businessmen and rest were students (6\%), Farmers (8\%) (Table 1).

Table 1: Socio demographic data of cases in the study.

\begin{tabular}{|lll|}
\hline Variable & Number & $\%$ \\
\hline Age group (in years) & & \\
\hline $11-20$ & 8 & 16 \\
\hline $21-30$ & 18 & 36 \\
\hline $31-40$ & 18 & 36 \\
\hline $41-50$ & 6 & 12 \\
\hline Occupation & & $\%$ \\
\hline Driver & 8 & 16 \\
\hline Farmer & 4 & 8 \\
\hline Business & 6 & 12 \\
\hline Worker & 21 & 42 \\
\hline Student & 3 & 6 \\
\hline Housewife & 8 & 16 \\
\hline
\end{tabular}

Table 2: Etiology of the injury among the cases in the study.

\begin{tabular}{|lll|}
\hline Etiology of injury & Number & $\%$ \\
\hline RTA & 15 & 30 \\
\hline Industrial Injury & 10 & 20 \\
\hline Trauma & 12 & 24 \\
\hline House injury & 6 & 12 \\
\hline Assault & 7 & 14 \\
\hline
\end{tabular}

Road traffic injury was the most common etiology in our study with $30 \%$ and followed in order the other aetiologies are trauma (24\%), Industrial injury (20\%), assault (14\%) and house injury (12\%) (Table 2). This shows clear dominance of RTA and trauma in our study. $32 \%$ of the cases had other associated injuries involving other bones and systems of the body.

A total of fifty-seven (57) fractures were identified in the present study. 38 fractures $(66.7 \%)$ were observed in the right hand and $19(33.3 \%)$ were observed in left hand. Metacarpals were the majority $(26 / 57,45.62 \%)$ to be involved followed in order by proximal phalanx $(36.84 \%)$ and distal phalanx $(10 / 57,17.54 \%)$. In majority of the cases, shaft was involved $(46 / 57,80.7 \%)$ followed by juxta articular $(6 / 57,10.52 \%)$ and Intra-articular $(5 / 57,8.78 \%)$. Thirty-six of fractures were comminuted $(63.16 \%)$, and rest were intra-condylar $(13.93 \%)$, shaft short oblique $(15.79 \%)$ and juxta articular $(5.26 \%)$ and shaft transverse $(1.75 \%)$ (Table 3$)$.

Table 3: Fracture parameters of the cases in the study.

\begin{tabular}{|lll|}
\hline Parameter & Number & $\%$ \\
\hline Injury at site of fracture & & \\
\hline Metacarpal & 26 & 45.62 \\
\hline Proximal phalanx & 21 & 36.84 \\
\hline Middle phalanx & 10 & 17.54 \\
\hline Site of fracture & & \\
\hline Shaft & 46 & 80.7 \\
\hline Juxta articular & 6 & 10.52 \\
\hline Intra articular & 5 & 8.78 \\
\hline Pattern of fracture & & \\
\hline Comminuted & 36 & 63.16 \\
\hline Intra articular unicondylar & 3 & 5.26 \\
\hline Intra articular bicondylar & 5 & 8.77 \\
\hline Juxta articular & 3 & 5.26 \\
\hline Shaft transverse & 1 & 1.75 \\
\hline Shaft short oblique & 9 & 15.79 \\
\hline
\end{tabular}

Table 4: Properties of fracture healing and UMEX duration.

\begin{tabular}{|c|c|c|}
\hline Variable & $\mathbf{N u}$ & $\%$ \\
\hline \multicolumn{3}{|c|}{ Fracture healing duration (in weeks) } \\
\hline $8-12$ & 35 & 61.4 \\
\hline $13-16$ & 11 & 19.3 \\
\hline $17-20$ & 7 & 12.3 \\
\hline$>20$ & 4 & 7.0 \\
\hline \multicolumn{3}{|c|}{ Duration of UMEX in situ (in weeks) } \\
\hline $3-4$ & 16 & 28.1 \\
\hline $5-6$ & 33 & 57.9 \\
\hline $7-8$ & 8 & 14.0 \\
\hline
\end{tabular}

Out of the 50 cases in the study, 42 cases were operated within 3 days of injury and eight cases between 4 to 7 days of injury. Cases operated within 3 days had a good outcome with $\mathrm{p}=0.01$.

Table 4, summarizes the properties of fracture healing and duration of UMEX in situ in weeks. $61.4 \%$ of cases had radiological union within $8-12$ weeks of the study. $19.3 \%$ of cases in 13-16 weeks, $12.3 \%$ had union in 17-20 weeks and only $7 \%$ above 20 weeks in the study. Duration of UMEX fixator in situ was 5-6 weeks in 57.9\% of cases, 34 weeks in $28.1 \%$ of cases and 7-8 weeks in $14 \%$ of cases. Mean duration of UMEX application was $38.12 \pm 2.4$ weeks. 
Of all the complications observed in the study, partial stiffness was the commonest with $52.17 \%$, and other less common were malunion (17.39\%), non-union $(13.04 \%)$, osteomyelitis, pin loosening $(4.35 \%)$ and pin tract infection $(8.7 \%)$. With regard to the functional outcome as per the Duncan's criteria, 44\% had good outcome, $40 \%$ had excellent outcome, $10 \%$ had fair and $6 \%$ had poor outcome in our study (Table 5).

\section{Table 5: Complications and final outcome of cases in} study.

\begin{tabular}{|lll|}
\hline Variable & Number & $\%$ \\
\hline Complication & \multicolumn{2}{l|}{} \\
\hline Mal union & 4 & 17.39 \\
\hline Non union & 3 & 13.04 \\
\hline Partial stiffness & 12 & 52.17 \\
\hline Osteomyelitis & 1 & 4.35 \\
\hline Pin loosening & 1 & 4.35 \\
\hline Pin tract infection & 2 & 8.70 \\
\hline Total & 23 & 40.35 \\
\hline Final outcome of cases in the study & \\
\hline Excellent & 20 & 40 \\
\hline Good & 22 & 44 \\
\hline Fair & 5 & 10 \\
\hline Poor & 3 & 6 \\
\hline
\end{tabular}

\section{DISCUSSION}

The present prospective study was conducted to evaluate the role of universal mini extractor in final outcome of cases of fractures of metacarpals and phalanges of the hand. A total of 50 cases which fulfilled the inclusion criteria were included and a total of fifty-seven fractures were managed by UMEX in our study. Male dominance was observed in our study with $80 \%$ of cases and the maximum age group was $21-40$ years. This is explained by the cause that males are more involved in physical works, risk jobs, traffic accidents and among the females the cause observed in Indian scenario was a few cases of kitchen injuries and domestic assault. Findings of our study were in according to the findings of Kamath et al who reported the male incidence as $78 \%$ and common age group of 2035 years in his study. ${ }^{6}$ The most common cause was road traffic injury which is on par with the findings of many studies universally. In few studies among the west occupational injury was cited as the most common cause of fractures of the metacarpal and phalanges, however the causes are variable in Indian scenario as most of them are involved in agricultural working and industrial injury accounted only to $20 \%$ among the cases in our study where Basar et al. $^{7}$

In our present study, all the cases included had open fractures or were involving the joint surface or multiple fractures which were difficult to manage conservatively. Majority of the cases $45.62 \%$ had fracture of metacarpal followed by proximal phalanx $(36.84 \%)$ and last the middle phalanx $(17.54 \%)$. Findings of our study were in clear association with findings of Soni et al who reported $56 \%$ of metacarpal and $44 \%$ of phalangeal fractures in their study. ${ }^{8}$ Dominant hand (right) was involved in $66.67 \%$ of cases in our study, however no significance was associated with this parameter with regard to outcome in our study.

Shaft was the most common site of fracture $(80.7 \%)$ in our study with other less common involving were juxta and intra articular site. In many studies conducted shaft was the most common site, however few studies reported that in trauma shaft was most commonly involved whereas in other less common causes like accidental or degeneration disorders intra/juxta articular was the most common site of fractures. These findings are variable depending upon the etiology of the fracture and are explained in many studies universally. ${ }^{9} 63.16 \%$ of fractures in our study were comminuted type and others were less common. Findings of our study were on par with the findings of $\mathrm{Xu}$ et al who reported $74 \%$ of fracture to be comminuted and transverse oblique in $14 \%$ of cases in their study. ${ }^{10}$ Presence of soft tissue injury directly affects final outcome of final range of movements comparable to Duncan study of 140 cases. This also corresponds with the Stickland and Kleiman who described factors influencing digital performance. ${ }^{11}$

In our present study fracture healing occurred within 8-12 weeks $(61.4 \%)$ and more than 20 weeks in only four cases which had associated multiple fractures, old age and delay in timing of surgery. The mean time of fracture healing in our study was 12.85 weeks. Findings of our study were consistent with the findings of studies in literature where average radiological healing of fractures of phalanges and metacarpals is 4-5 months and 1-17 months. ${ }^{12}$

In the present study, UMEX fixator was removed in $57.9 \%$ of cases within 5-6 weeks, $28.1 \%$ in 3-4 weeks and $14 \%$ of cases it was 7-8 weeks. The mean duration of UMEX in situ was 5.6 \pm 1.2 weeks in our study. Findings in our study correlated with the findings of Blazar et al. ${ }^{13}$

When coming to the complications observed in our study, partial stiffness was the commonest seen in $52.17 \%$ of cases, a joint was considered partially stiff when the range of motion in that particular finger was $\angle 180^{\circ}$ and $\angle 100^{\circ}$ in case of thumb. The cases which developed stiffness were open injuries, late reported cases, multiple fractures or comminuted fractures. Pin tract infection and pin loosening was observed in three cases in our study. Malunion was observed in four cases and was due to post reduction collapse.

Out of the 26 fractures involving metacarpals, 12 had excellent outcome, 8 were good, four were fair and two had poor outcome. Out of 31 fractures involving the phalanx, eight has excellent outcome, 14 good outcomes, one was fair and one had poor outcome. Cases with less age had significantly excellent and good outcome than with higher age group. 


\section{CONCLUSION}

To conclude, most of the metacarpal and phalangeal fractures of the hand cane be managed conservatively unless emergency requirements are to be met. Cases with multiple/comminuted/intra articular fractures require operative reduction and stabilization for early movement and better healing. Findings from our study suggest that, UMEX is an adequate treatment modality for multiple, intra articular and open fractures. It's also simple to operate with fewer complications. Understanding the basic principles and correct application methodology is absolutely essential for optimal usage of the equipment. It's an additional and useful tool in management of small fractures of the hand.

\section{Funding: No funding sources}

Conflict of interest: None declared

Ethical approval: The study was approved by the institutional ethics committee

\section{REFERENCES}

1. Sheshadri SI. External fixation of metacarpal and phalangeal fractures. J Hand Surg. 1991;16(3):54450.

2. Gupta R, Singh R, Siwach R. Evaluation of surgical stabilization of metacarpal and phalangeal fractures of hand. Indian J Orthop. 2007;41(3):224-9.

3. Hove LM. Fractures of the Hand. Scandinavian $\mathbf{J}$ Plastic Reconstructive Surg Hand Surg. 1993;27(4):317-9.

4. Richard W, Duncan MD. Open hand fractures: An analysis of the recovery of active motion and of complications. J Hand Surg. 1993;18(3):387-94.

5. Swanson, Todd V. Open hand fractures: Prognosis and classification. J Hand Surg. 1976;16(1):101-7.
6. Kamath JB, Harshvardhan, Naik DM, Bansal A. Current concepts in managing fractures of metacarpal and phalangess. Indian J Plast Surg. 2011;44(2):203-11.

7. Basar H, Basar B, Basci O. Comparison of treatment of oblique and spiral metacarpal and phalangeal fractures with mini plate plus screw or screw only. Arch Orthop Trauma Surg. 2015;135:499-504.

8. Soni A, Gulati A, Bassi JL. Outcome of closed ipsilateral metacarpal fractures treated with mini fragment plates and screws: a prospective study. J Orthopaed Traumatol. 2012;1(13):29-33.

9. Freeland AE, Orbay JL. Extraarticular hand fractures in adult. Clin Orthop Relat Res. 2006;445:133-45.

10. Xu J, Zhang C. Mini-plate versus Kirschner wire internal fixation for treatment of metacarpal and phalangeal fractures in Chinese Han population: a meta-analysis. J Orthop Surg Res. 2014;9(24):10517.

11. Strickland JW, Steichen JB, Kleinman WB, Hasting HJ, Flynn N. Phalangeal fractures: factors influencing digital performance. Orthop Rev. 1982;11:39-50.

12. Mohammed R, Farook MZ, Newman K. Percutaneous elastic intramedullary nailing of metacarpal fractures: surgical technique and clinical results study. J Orthop Surg Res. 2011;6(1):37.

13. Blazar PE, Leven D. Intramedullary nail fixation for metacarpal fractures. Hand Clin. 2010;26(3):3215.

Cite this article as: Vijayanand $\mathrm{A}$, Penchalaih $\mathrm{A}$. An assessment of functional outcome and management of metacarpal and phalangeal fractures of hand with universal mini external fixator. Int $\mathbf{J}$ Res Orthop 2020;6:682-6. 